\title{
Conversion of U-238 and Th-232 Using a Fusion Neutron Source
}

\author{
Xianjun Zheng1, Baiquan Deng2*, Wei Ou³, Fujun Gou ${ }^{3}$ \\ ${ }^{1}$ HOPE Innovations Inc., Ontario, Canada \\ ${ }^{2}$ Southwestern Institute of Physics, Chengdu, China \\ ${ }^{3}$ Institute of Nuclear Science and Technology, Sichuan University, Chengdu, China \\ Email: ${ }^{*}$ dengbq@swip.ac.cn
}

Received 16 July 2014; revised 30 August 2014; accepted 14 September 2014

Copyright (C) 2014 by authors and Scientific Research Publishing Inc.

This work is licensed under the Creative Commons Attribution International License (CC BY).

http://creativecommons.org/licenses/by/4.0/

(c) (i) Open Access

\section{Abstract}

This article proposes a general framework for the conversion of U-238 and Th-232 utilizing fusion-produced neutrons. This recognizes that emerging fusion technologies may not produce sufficient net energy output to justify stand-alone applications, yet may be commercially viable for breeder transmutation or hybrid fusion-fission reactor concepts proposed herein to dispose of nuclear wastes and long life high radioactive fission products remaining in shutdown nuclear power plants. Results show that this could be achievable within a decade, given an appropriate fusion source. However, if $20 \%$ beryllium of nuclei density is added to the convertor blanket, the efficiency of the conversion process can be significantly increased. Also, the neutron energy spectrum resulting from dense D-D plasma core fusion is much softer than D-T fusion neutron source, hence the probability of $(n, p)(n, \alpha)$ backward decay reaction paths will be smaller and the conversion efficiency will be elevated.

\section{Keywords}

\section{Conversion, Breeder, D-D Fusion}

\section{Neutron Capture by U-238}

In any operating nuclear reactor containing U-238, some plutonium-239 will accumulate in the nuclear fuel due to continuous neutron capture by U-238 followed by two-beta decays. Plutonium present in reactor fuel can absorb neutrons and fission just as U-235 can. Fission of plutonium-239 provides about one-third of the total energy produced in a typical commercial nuclear power plant. Spent nuclear fuel commonly contains about $0.8 \%$

\footnotetext{
${ }^{*}$ Corresponding author.
} 
of plutonium-239. This compares with $0.9 \%$ of U-235 and suggests that the fission reaction rate for plutonium-239 is approximately $10 \%$ faster than that of $\mathrm{U}-235$ in a typical commercial thermal nuclear reactor.

Considering light water reactors, U-235 is enriched to approximately $3 \%$ where $2.1 \%$ of it is burned during reactor operation. This suggests that $1.05 \%$ of plutonium-239 is burned during reactor operation (one-half of $2.1 \%$ and one-third of the total). Therefore, a light water reactor generates $1.85 \%(0.8 \%+1.05 \%)$ plutonium during reactor operation. Considering one U-238 absorbs a neutron and after two-beta decays resulting in plutonium-239, the neutron capture rate of U-238 is calculated to be nearly $90 \%$ of the fission rate for U-235, largely due to the high concentration of U-238 ( $>95 \%$ of the loading uranium fuel).

During normal reactor operation, a U-235 nucleus continuously absorbs a thermalized neutron and releases on average 2.43 neutrons. One of which is consumed to split another U-235 (after moderation to thermal neutron) in order to sustain chain reaction. The above simple calculation demonstrates that about 0.9 neutrons are captured by U-238 (to breed plutonium-239). The remaining 0.53 neutrons are lost in the environment that includes neutron absorption in water, reactor components and concrete building.

\section{A Pure Converter Concept}

It is possible to design a pure converter that only converts U-238 existed within nuclear waste ( $>95 \%)$ into nuclear fuel, without the need to generate power. The advantages of such a simple converter include, but not limited to, operation in the temperature range between $0^{\circ} \mathrm{C}$ and $100^{\circ} \mathrm{C}$ and under atmosphere pressure. This can remove many engineering challenges for the design of brand new fusion/fission hybrid reactors and thus permit designers to focus on the conversion related issues, for example, component material embrittlement due to neutron flux as well as irradiation damage such as voids, bubbles, cracks, etc.

In order to maximize the conversion rate turning U-238 into plutonium-239, the converter may be designed to work in the intermediate neutron energy range between, for example, $10 \mathrm{and} 1000 \mathrm{eV}$, i.e., the resonance absorption peaked domain shown in Figure 1. The neutron absorption rate is greatly enhanced for U-238, by at least ten times. Meanwhile, the fission rates for U-235 and plutonium-239 can be reduced by at least 50\%. Consequently, it is anticipated that $>90 \%$ of the neutron source can be used for converting U-238 into plutonium-239, based on below estimation: 9 neutrons for conversion, 0.5 neutrons lost to the environment and 0.5 neutrons split fissile fuel nuclei into two. A simple converter concept is shown in Figure 2.

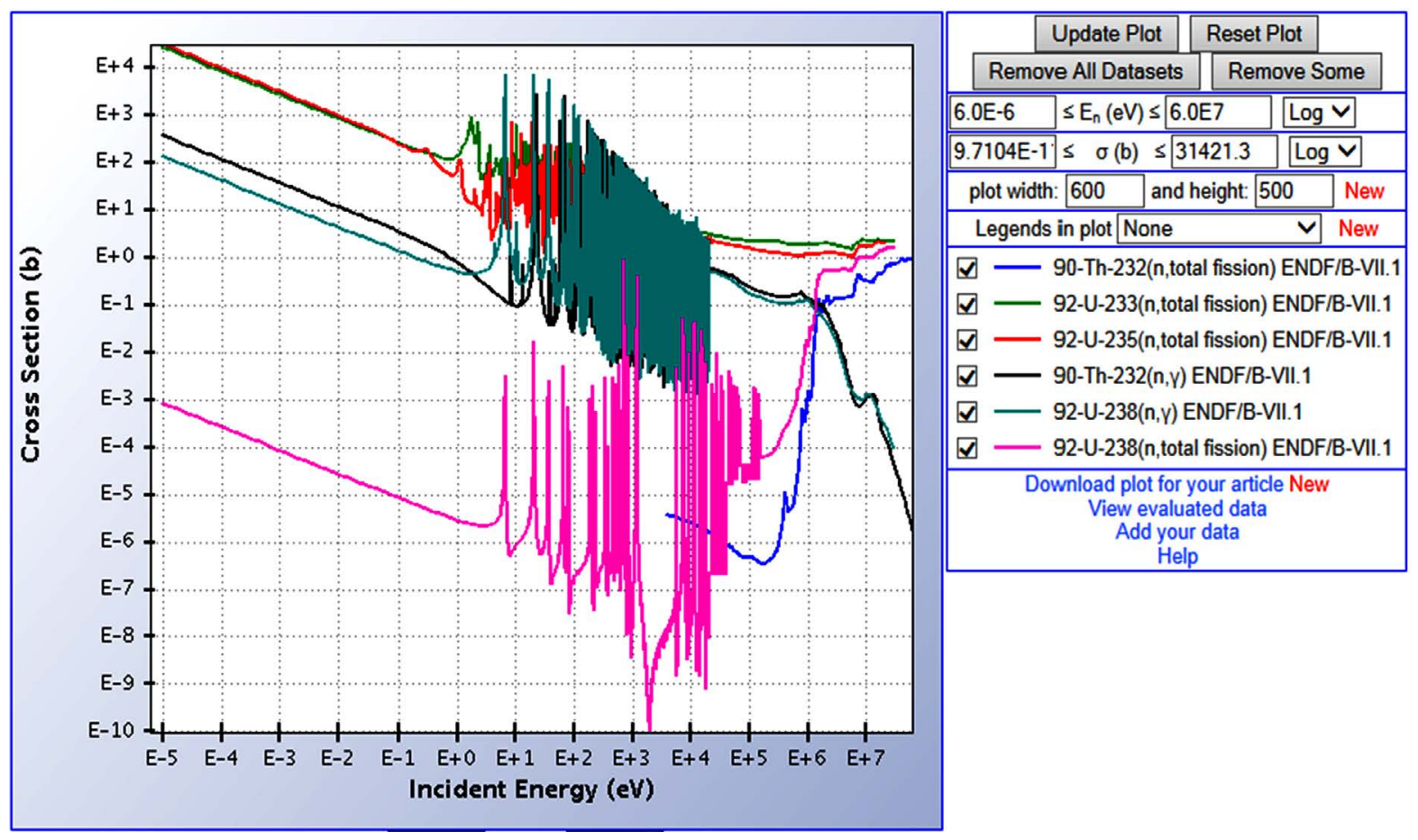

Figure 1. Fission and neutron capture rates for uranium and thorium. 


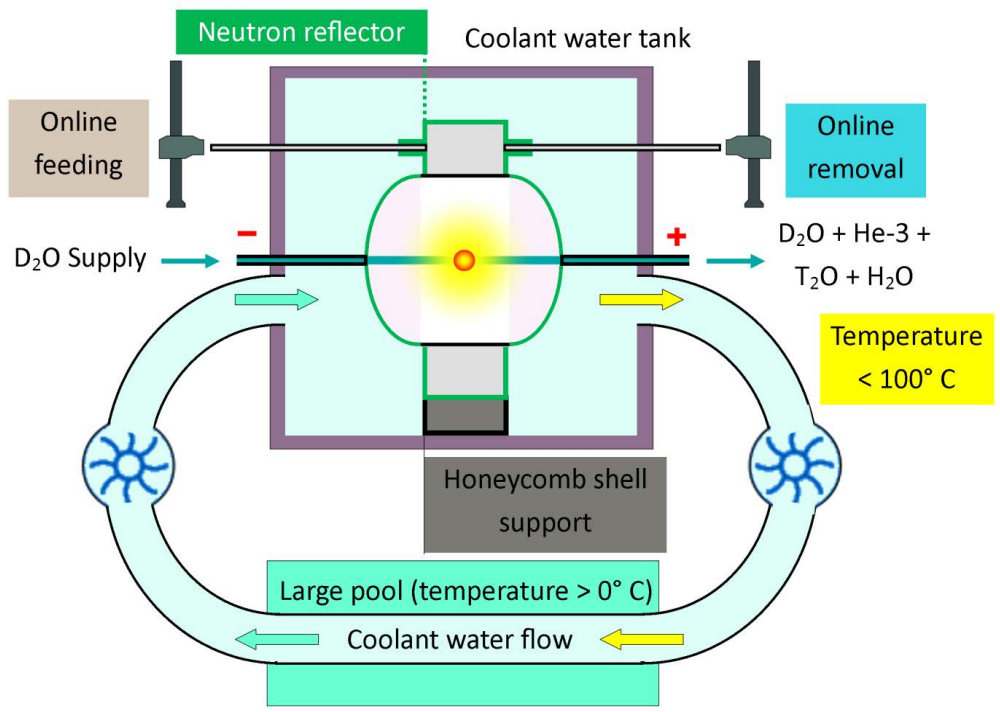

Figure 2. Overview of fuel converter driven by neutron source at fusion chamber.

\section{D-D Fusion and Conversion Rate}

There are two branches of D-D fusion reaction, each with 50\% probability of occurrence,

$$
\begin{aligned}
& { }_{1}^{2} \mathrm{D}+{ }_{1}^{2} \mathrm{D} \rightarrow{ }_{2}^{3} \mathrm{He}(0.82 \mathrm{MeV})+{ }_{0}^{1} n(2.45 \mathrm{MeV}) \\
& { }_{1}^{2} \mathrm{D}+{ }_{1}^{2} \mathrm{D} \rightarrow{ }_{1}^{3} \mathrm{~T}(1.01 \mathrm{MeV})+{ }_{1}^{1} p(3.02 \mathrm{MeV})
\end{aligned}
$$

The above two branches give a total energy release of $7.3 \mathrm{MeV}\left(1.1696 \times 10^{-12} \mathrm{~J}\right)$ and release a neutron with $2.45 \mathrm{MeV}$ energy. Considering a net power output of $1 \mathrm{GW}$, associated with a gross power of $3.333 \mathrm{GW}$, here assuming a thermoelectric conversion efficiency of $30 \%$, the corresponding fusion neutron yield can be calculated as follows,

$$
I_{\text {neutron }}^{D D}=\frac{3.333 \mathrm{GW}}{7.3 \mathrm{MeV}}=\frac{3.333 \times 10^{9} \mathrm{~J} / \mathrm{s}}{1.1696 \times 10^{-12} \mathrm{~J}}=2.85 \times 10^{21} / \mathrm{s}
$$

Tritium and helium-3 gas collections per day are calculated as follows,

$$
M_{\text {helium-3 }}^{\text {day }} \cong M_{\text {tritium }}^{\text {day }}=24 \times 3600 \times 2.85 \times 10^{21} \times 3 \times 1.66 \times 10^{-27} \mathrm{~kg}=1.23 \mathrm{~kg}
$$

HOPE Innovations patented dense plasma D-D fusion process [1] is expected to immediately burn some of the resulting tritium and helium-3 nuclei and the remaining He and tritium may be collected and stored in tanks for future usage with other fusion approaches such as D-T or advanced D-He3 fusion [2] [3]. D-T fusion will generate neutrons with $14.1 \mathrm{MeV}$ energy, which is suitable for transmutation of nuclear waste.

Considering Equation (3), as well as a fuel conversion rate of $90 \%$, the net electric power conversion rate for one operating converter is calculated as

$$
R=\frac{1 \mathrm{GW}}{7.3 \mathrm{MeV}} \times 90 \% \times 200 \mathrm{MeV}=24.66 \mathrm{GW}
$$

In order to demonstrate how rapidly a converter can convert nuclear waste into nuclear fuel, let us consider an example based on the Pickering nuclear reactors in Ontario, Canada, with a net capacity of 4.12 GW. By 2014, Pickering has been operating for an average of 37 years, with its A and B stations starting in 1971 and 1983, respectively. The number of years required for one converter to completely convert the nuclear waste accumulated at the Pickering site so far is calculated as follows: 


$$
Y=\frac{4.12 \mathrm{GW}}{24.66 \mathrm{GW}} \times 37 \text { years }=6 \text { years }
$$

Compared to U-238, thorium-232 behaves in a similar way. Consequently, a pure converter can also convert thorium-232 into U-233 (fissile material).

However, if $20 \%$ beryllium (as nuclei density) is loaded together with the waste fuel, the time required to completely dispose the nuclear waste accumulated in the Canadian Pickering nuclear power plant can be shortened by up to $20 \%$.

Figure 3 describes the current Chinese nuclear fuel cycle, including re-cycling of PWR nuclear waste for use in $\mathrm{CANDU}^{\circledR}$ reactors in Qinshan [4]. The converter concept presented here can be an ideal candidate to close the loop of the fuel cycle. The final nuclear waste from the Qinshan CANDU units (end of fuel cycle) may be converted to become the fuel for PWR reactors (beginning of fuel cycle).

\section{Breeder and Hybrid Reactors [5]-[7]}

A breeder reactor can convert fertile material, such as U-238 and Th-232, as fast as it burns fissile material, such as plutonium-239 and U-233, during reactor operation. A possible breeder reactor concept is shown in Figure 4. Such a breeder reactor can work in a neutron energy range between, for example, 0.1 and $1000 \mathrm{eV}$, in order to achieve adequate plutonium-239 or U-233 burning rates. Meanwhile, it is capable of converting U-238 or thorium-232 to fuel at the same rate in order to sustain the nuclear reaction.

If the concentration of plutonium-239 increases, for example, the reactor power increases. This situation may be offset by lowering the D-D fusion neutron yield by, for example, reducing the fusion fuelling rate. This will, in turn, decrease the neutron capture rate of U-238 and eventually bring the concentration of plutonium-239 back to normal. On the other hand, if the concentration of plutonium-239 becomes lower, the reactor power decreases. In this case, the fusion reaction rate can be increased in order to bring reactor power and the concentration of plutonium-239 back to normal.

As an alternative to a breeder reactor, it is also possible to split the nucleus of a U-238 atom by a fast neutron with energy exceeding $1 \mathrm{MeV}$. In order to incorporate this behavior, a fusion / fission hybrid reactor can be designed to work in the neutron energy range of $2-14 \mathrm{MeV}$. A possible hybrid reactor concept is shown in Figure 5. The fission rate of U-238 for fast neutrons with energy $>2 \mathrm{MeV}$, Figure 1, can be optimized to match or exceed its absorption rate for thermal neutrons (observed to be significant enough to initiate plutonium-239 burning process in current nuclear power plants). For example, we may consider D-T fusion reactions that can generate high-energy fusion neutrons (14.1 MeV), Figure 5.

\section{Conclusion}

A pure converter concept, using dense plasma D-D fusion-produced neutrons, is proposed, and the potential conversion rates are discussed. Breeder and hybrid reactor approaches also have been considered in this article.

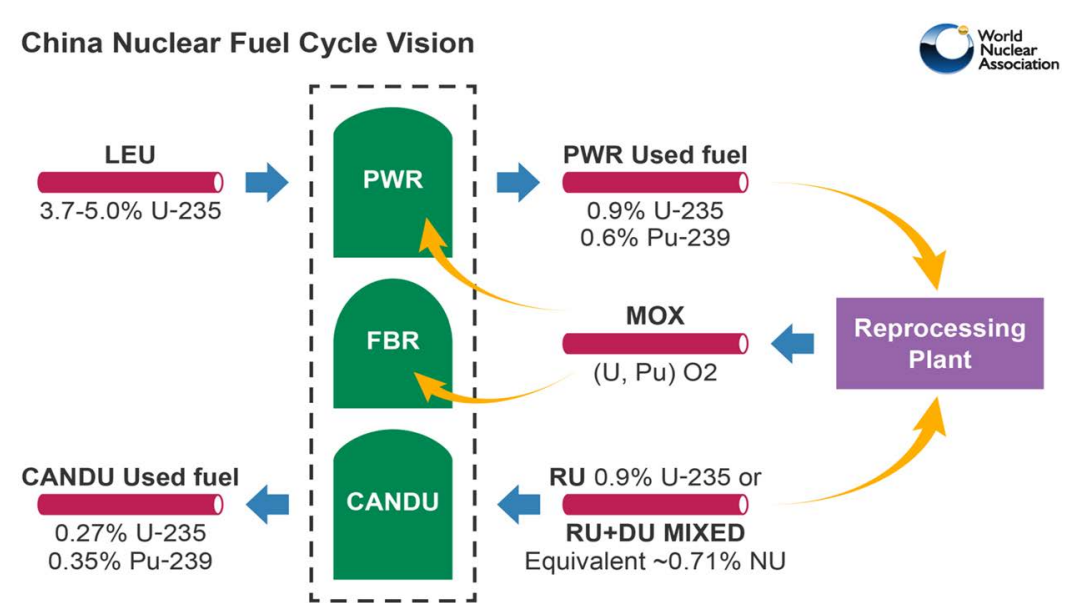

Figure 3. Illustration of Chinese nuclear fuel cycle [4]. 


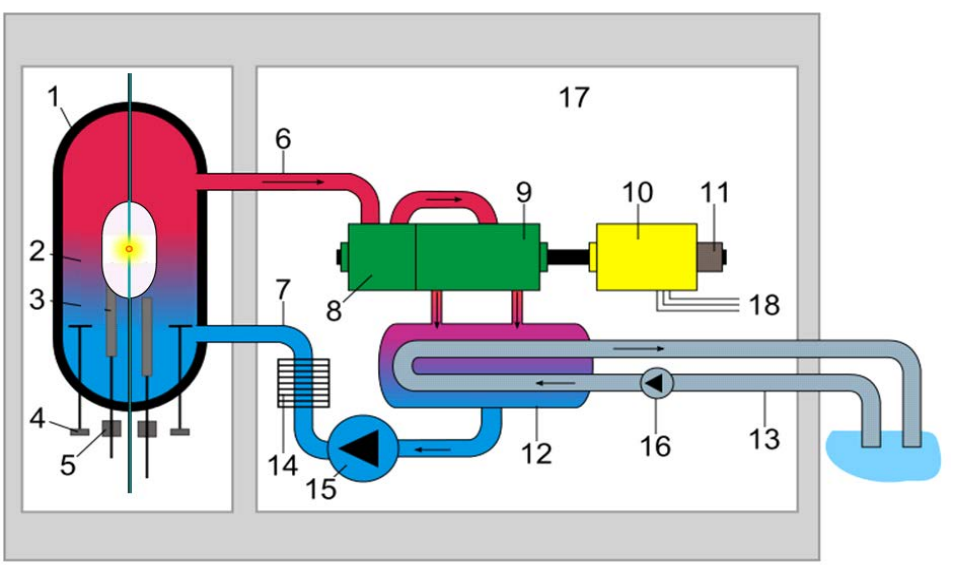

1 reactor vessel

2 fuel chamber

3 control rod element

4 circulation pumps

5 control rod motors

6 steam

7 inlet circulation water

8 high pressure turbine

9 low pressure turbine

10 electric generator

11 electrical generator exciter

12 steam condenser

13 cold water for condenser

14 pre-warmer

15 water circulation pump

16 condenser cold water pump

17 concrete chamber

18 connection to electricity grid

Figure 4. A breeder reactor based on modification of boiling water reactor.

\section{PRESSURISED-WATER REACTOR}

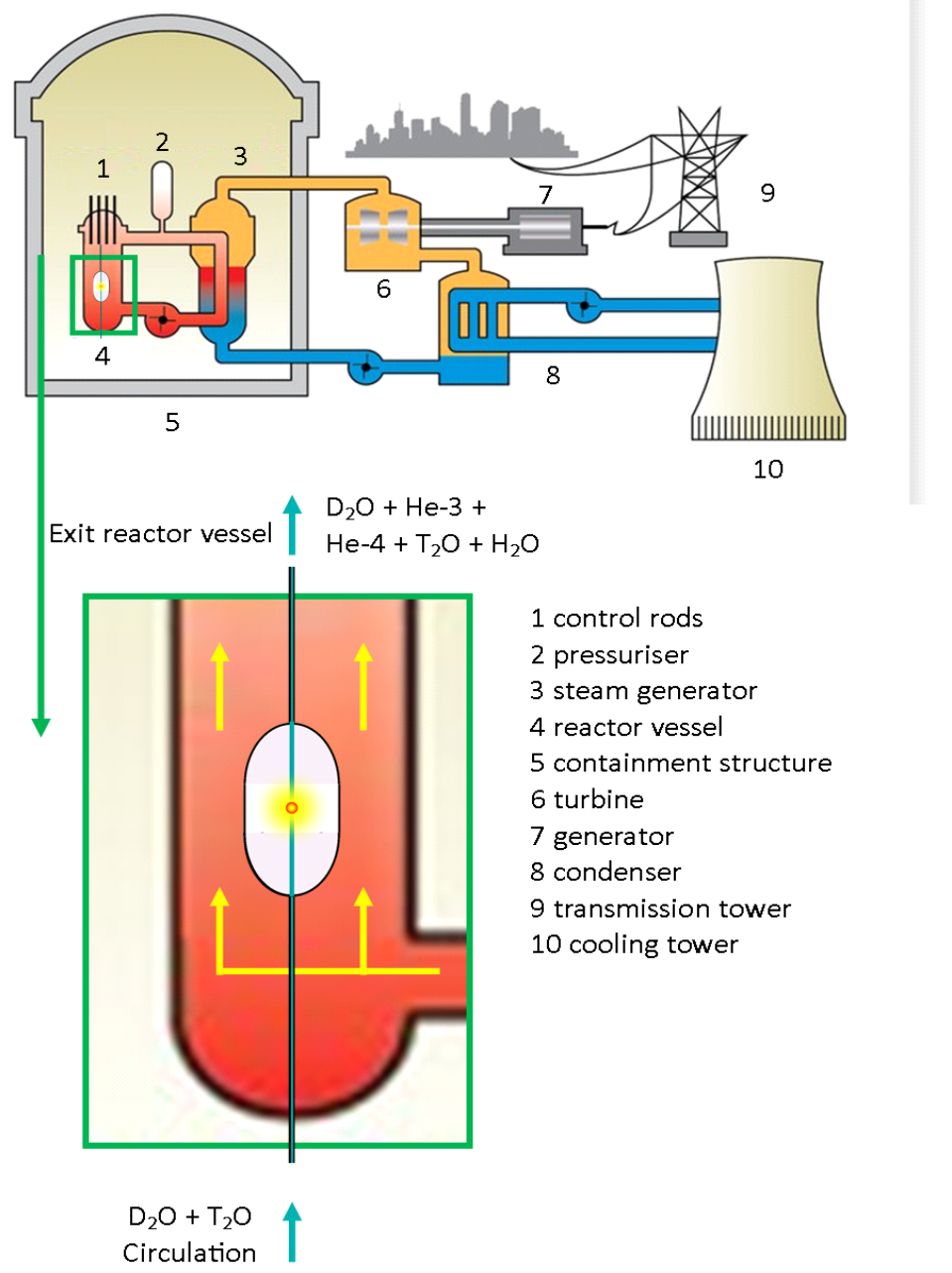

Figure 5. A fusion/fission hybrid reactor based on modification of light water reactor. 
However, if $20 \%$ beryllium of nuclei density is also loaded into the convertor, the time required to completely dispose the nuclear wastes accumulated in the Canadian Pickering nuclear power plant will be shortened by up to $20 \%$. The neutron energy spectrum of D-D fusion is much softer than D-T fusion neutron source, hence the probability of $(n, p)(n, \alpha)$ backward decay reaction channels will be smaller and conversion efficiency will be elevated.

\section{Acknowledgements}

The authors are grateful to Linna Zheng for her excellent modified figures, also to Dr. Willy Liu and Mickey Masuda for their efforts and all beneficial discussions in completing this work

\section{Funding}

This research is supported by ITER program special Grant No. 2013GB114003, and National Natural Science Foundation of China, Project approval No.: 11275135.

\section{References}

[1] Zheng, X.J. (2012) Continuous Fusion Due to Energy Concentration through Focusing of Conversing Fuel Particle Beams. International Patent Application No. PCT/CA2012/050392; Our Ref.: 21906-P39161PC00.

[2] Ou, W., Zheng, X.-J., Deng, B.-Q. and Gou, F.-J. (2014) Chinese Physics Letters, (to Be Published).

[3] Deng, B.Q. (2013) Fusion Reactor Physics-New Conception and New Technology. Chinese Atomic Energy Press, Beijing, Chapter 15-19, 129-166.

[4] Xiao, M. (CGN) (2013) Status and Perspective of Spent Fuel Management and Fuel Cycle in China. WNA Plenary Session. http://www.world-nuclear.org/info/Country-Profiles/Countries-A-F/China--Nuclear-Fuel-Cycle

[5] Deng, B.Q., Li, Z.X. and Feng, K.M. (2011) Tritium Well Depth, Tritium Well Time and Sponge Mechanism for Reducing Tritium Retention. Nuclear Fusion, 51, Article ID: 073041. http://dx.doi.org/10.1088/0029-5515/51/7/073041

[6] Deng, B.Q., Li, X.Z., Huang, J.H., et al. (2004) Computer Simulation of Tritium Inventory and Leakage of the Fusion Experimental Reactor of FEB-E. Fusion Science and Technology, 46, 548.

[7] Deng, B.Q., Allain, J.P. and Lou, Z.-M. (2007) Near Surface Bipartition Model for the Study of Material Response of Plasma-Facing Surfaces Exposed to Energetic Charged Particles. Nuclear Instruments and Methods in Physics Research Section B, 259, 847-852. 
Scientific Research Publishing (SCIRP) is one of the largest Open Access journal publishers. It is currently publishing more than 200 open access, online, peer-reviewed journals covering a wide range of academic disciplines. SCIRP serves the worldwide academic communities and contributes to the progress and application of science with its publication.

Other selected journals from SCIRP are listed as below. Submit your manuscript to us via either submit@scirp.org or Online Submission Portal.
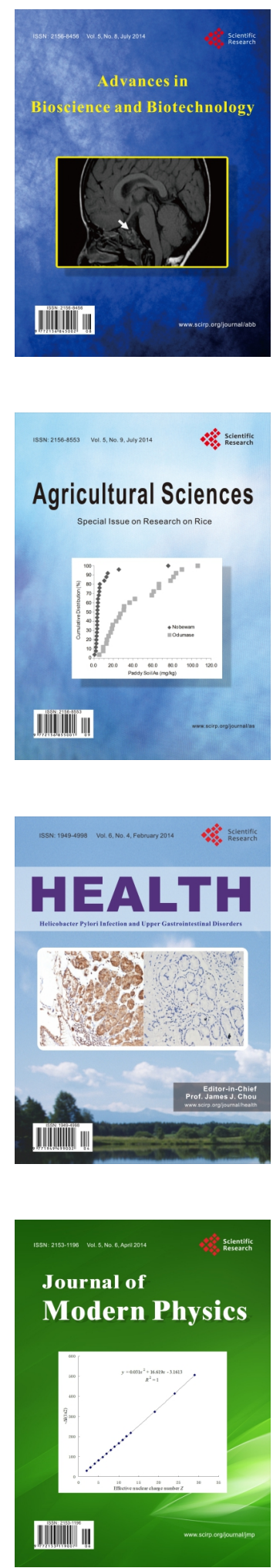
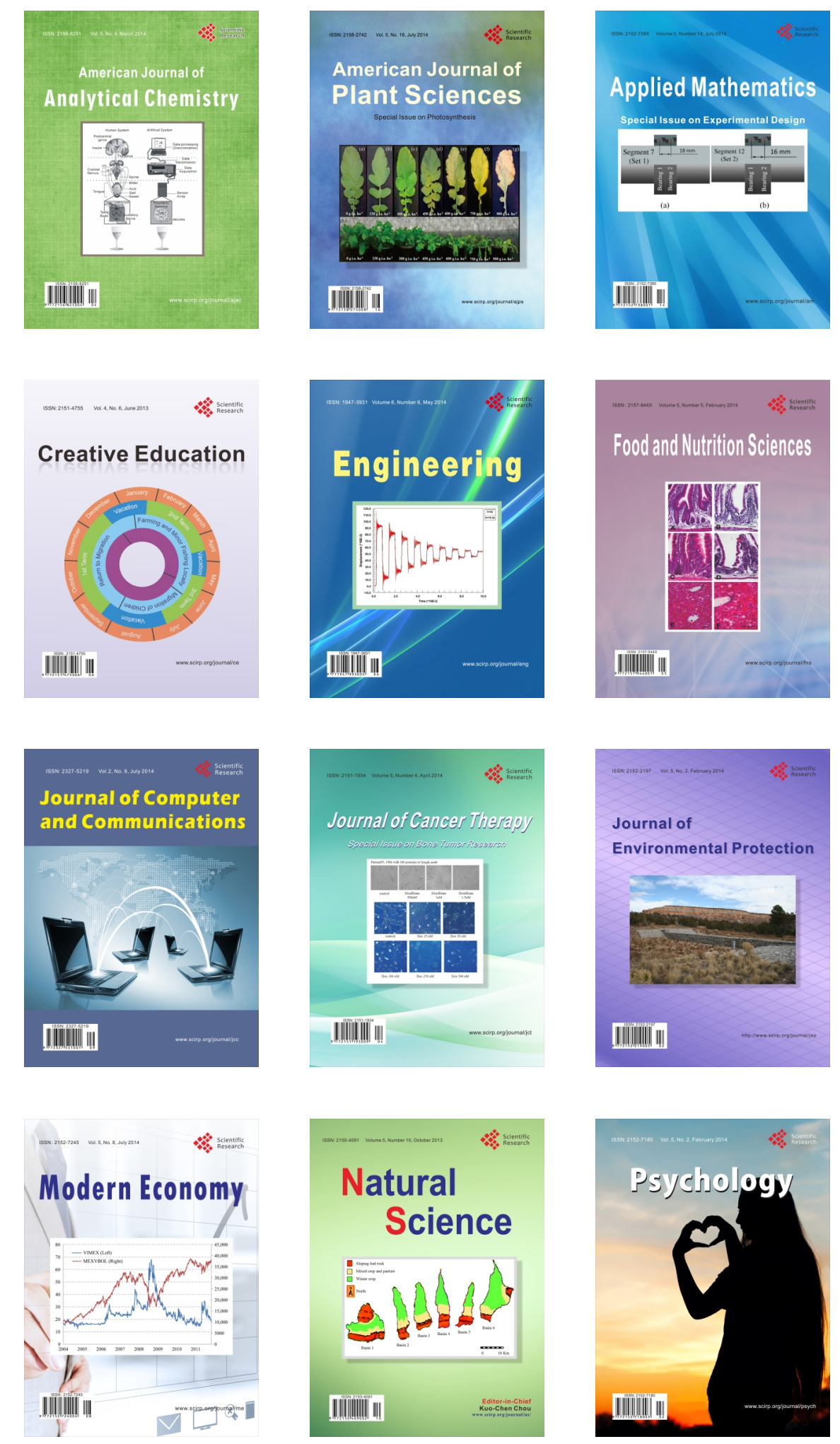